\title{
Effects of Rotational Feed Emulating Four-Die Radial Forging on Forged Shape in Mandrel-Less Incremental Forging of Thick Circular Tube
}

\author{
Takahiro Makiyama* \\ * Department of Mechanical and Production Engineering \\ Institute of Technologists \\ 333 Maeya, Gyoda, Saitama, 361-0038, Japan \\ e-mail: makiyama@iot.ac.jp, web page: http://www.iot.ac.jp/english/
}

\begin{abstract}
Tubes with variable wall thickness corresponded to their load distribution have advantages in weightsaving and resource-saving. Because of the advantages, those tubes are applied to bicycles frame and proposed to apply automotive driveshafts [1] and railway axles [2]. Those tubes should be tailormade to reduce their weight effectively; therefore, flexible forming is suitable for their production. Most tubes with variable wall thickness are produced by radial forging, rotary swaging, cross-wedge rolling, and drawing. Those forming processes are relatively flexible; however, their dies and mandrels have to be prepared according to the tubes' size to be produced.

The author proposed a new incremental forging to produce tubes with variable wall thickness [3]. A circular tube is placed between two simple flat dies and held by a manipulator. No mandrels are used. Initially, the tube is compressed by the dies in the radial direction. Then, the tube is rotated by the manipulator around the longitudinal direction. After that, the compression and rotation are repeated alternately until an intended forging number. This incremental forging does not require preparing special dies and mandrels regardless of the tubes' size to be produced.

One of the difficulties in the proposed incremental forging is to obtain the forming conditions to produce desired shapes because the tube freely deforms except a small area where the two flat dies are contacted. To examine the possibility of formability improvement, the author conducted finite element simulation using commercial software FORGE. As a fundamental research, the effects of rotational feed emulating four-die radial forging on forged shape ware clarified in this study.
\end{abstract}

\section{REFERENCES}

[1] H. W. Raedt, T. Wurm and A. Busse, "The Lightweight Forging Initiative - Phase III: Lightweight forging design for hybrid cars and heavy-duty truck", ATZ worldw., 121-4, 54-59, (2019).

[2] Z. Pater, "A comparative analysis of forming railway axles in 3- and 4-roll rolling mills", Mater., 13-14, 3084, (2020).

[3] T. Makiyama, "Effects of rotational feed at constant angles on forged shape in mandrel-less incremental forging of thick circular tube", J. Jpn. Soc. Technol. Plast., (in press). 